\title{
Impairment in the activities of daily living in older adults with and without osteoporosis, osteoarthritis and chronic back pain: a secondary analysis of population-based health survey data
}

\author{
Tanja Alexandra Stamm ${ }^{1 *}$, Karin Pieber ${ }^{2}$, Richard Crevenna ${ }^{2}$ and Thomas Ernst Dorner ${ }^{3}$
}

\begin{abstract}
Background: Independence in performing activities of daily living (ADLs) is a central aspect of functioning. Older adults frequently experience impairments and limitations in functioning in various life areas. The aim of this survey was to explore the limitations in the ADLs in older adults in a population-based survey in Austria.

Method: A population-based cross-sectional study in 3097 subjects aged $\geq 65$ years who were included in the Austrian health interview survey was performed. Descriptive statistics were used to calculate frequencies of problems in the ADLs. A principal component analysis was applied to analyze the main dimensions of 19 ADL items. Binary logistic regression models were used with the ADL dimensions as the dependent variables and osteoarthritis, chronic back pain, osteoporosis, sex, education level, anxiety or depression, age and pain intensity as independent variables.

Results: People with musculoskeletal conditions were significantly more often affected by ADL problems than people without these diseases. The ADL domain which caused problems in the highest proportion of people was "doing heavy housework" (43.9\%). It was followed by the ADL domains "bending or kneeling down" (39.3\%), "climbing stairs up and down without walking aids" (23.1\%), and "walking 500 m without walking aids" (22.8 \%). The principal components analysis revealed four dimensions of ADLs: (1) intense "heavy burden" ADLs, (2) basic instrumental ADLs, (3) basic ADLs and (3) hand-focused ADLs. The proportion of subjects who had problems with the respective dimensions was 58.2, 29.2, 23.0, and 9.2\%. Anxiety/depression (greatest effect), followed by the chronic musculoskeletal disease itself, female sex, higher age and pain intensity were significant predictors of ADL problems.
\end{abstract}

Conclusion: This population-based survey indicates that older people have considerable ADL problems. More attention should be paid to the high impact of pain intensity, anxiety and depression on ADLs.

Keywords: Activities of daily living, Population-based study, Occupational therapy

\footnotetext{
* Correspondence: tanja.stamm@meduniwien.ac.at

${ }^{1}$ Section for Outcomes Research, Center for Medical Statistics, Informatics, and Intelligent Systems, Medical University of Vienna and Division of Rheumatology, Department of Internal Medicine III, Medical University of Vienna, Spitalgasse 23, 1090 Vienna, Austria

Full list of author information is available at the end of the article
} 


\section{Background}

Worldwide, musculoskeletal diseases have major individual, societal, and economic implications. The most common musculoskeletal diseases, osteoarthritis, osteoporosis, and back pain lead to impairments in quality of life and in the activities of daily living (ADLs); as a consequence, they further lead to dependency, institutionalisation and increased health-care costs [1]. These musculoskeletal diseases have been defined as one of the major health priorities both on international level $[2,3]$ as well as on national level $[4,5]$.

Independence in the ADLs is a central aspect of functioning. Older adults with and without musculoskeletal complaints frequently experience impairments and limitations in functioning in various life areas [2]. Functioning is a comprehensive concept which includes different types of activities, such as self-care, productivity, leisure and rest, as well as the context in which an activity is performed. The most commonly used conceptual framework to describe functioning that includes all these factors is the World Health Organisation (WHO) International Classification of Functioning Disability and Health (ICF) [6]. In the ICF, functioning is defined as the interplay of the so-called ICF components body functions, body structures, activities and participation, as well as environmental and personal factors.

In qualitative studies, people with different types of arthritis described ADLs including self-care as important "problem areas" of all activities performed during a normal day [7-10]. Common symptoms of musculoskeletal conditions, such as pain, morning stiffness, lack of energy and fatigue, but also the lack of support and understanding by other people lead to ADL problems. While these qualitative studies allow us to better understand the life world of other people and to describe potential causes of problems from an inside perspective, population-based surveys are needed to demonstrate the number of people having certain ADL problems. Moreover, if ADL problems increase, they raise the need for additional support and costs for the individual as well as for health and social care institutions [1]. To estimate costs of health and social care, data are needed on (problems with) ADLs of older adults. Furthermore, personal (e.g. sex) and socio-economic factors, as well as comorbidities, pain intensity and anxiety may influence ADL abilities [11]. As health and social care systems differ between countries, Austrian data allow us to describe the current situation in our country, but also to compare our data to other countries. Apart from increased costs, older adults who stop performing ADLs lose the ability to perform these activities independently themselves $[12,13]$.

The aim of this survey was therefore to explore the limitations in ADLs in older adults with and without osteoporosis, osteoarthritis and chronic back pain (CBP) in a population-based survey in Austria including a discussion on the consequences for society.

\section{Methods}

A population-based cross-sectional study in 3097 subjects aged $\geq 65$ years who were included in the Austrian health interview survey was performed.

\section{Participants}

The database used for our analysis was the Austrian Health Interview Survey (AT-HIS) 2006-07 [14]. This survey was commissioned by the Austrian Federal Ministry of Health, Family and Youth (in German: Bundesministerium für Gesundheit, Familie und Jugend) and was carried out by Statistics Austria. The survey is the latest edition of a repetitively performed micro-census of a representative sample of the entire Austrian population, regardless of health status, with the aim to gain knowledge about subjective health, health behaviour, and utilisation of the health care system. The sample was stratified by geographic region, with the same number of subjects being included from each region. The subjects were interviewed between March 2006 and March 2007 by trained interviewers. The gross sample size was 25,130 people, older than 15 years, of which 24,509 were reached. 9,656 subjects were excluded. Out of them 5,709 subjects refused or broke off the interview, 3,308 were excluded due to difficulties in contacting them or because of deficiency in the German language, and in 639 cases there was an insufficiency in data quality. The data of a total of 15,474 subjects was eligible for analysis, thus the response rate was $63 \%$. The interviews were conducted face-to-face. The questionnaire was designed based on the European Core Health Interview Survey (EC-HIS) [15] and has been adapted for Austria by an expert panel. In order to account for the stratification of the sample the data were weighted by geographic region, age and sex. Missing values were systematised. For this analysis, only data of people older than 65 years were used. Thus, data of 1259 men and 1838 women were eligible for analysis.

\section{Assessment and survey questions}

The musculoskeletal diseases osteoarthritis, CBP, and osteoporosis were assessed with the questions: "Have you ever had osteoarthritis (abrasion or damage of joints), arthritis (inflammation of joints), or rheumatic joint diseases?", "Have you ever had chronic pain in your spinal column (low back, neck or upper back)?" and "Have you ever had osteoporosis (decrease of bone mass)?"

For the assessment of ADLs, 19 different questions of the AT-HIS were used (Table 1). 
Table 1 Assessment of ADLs

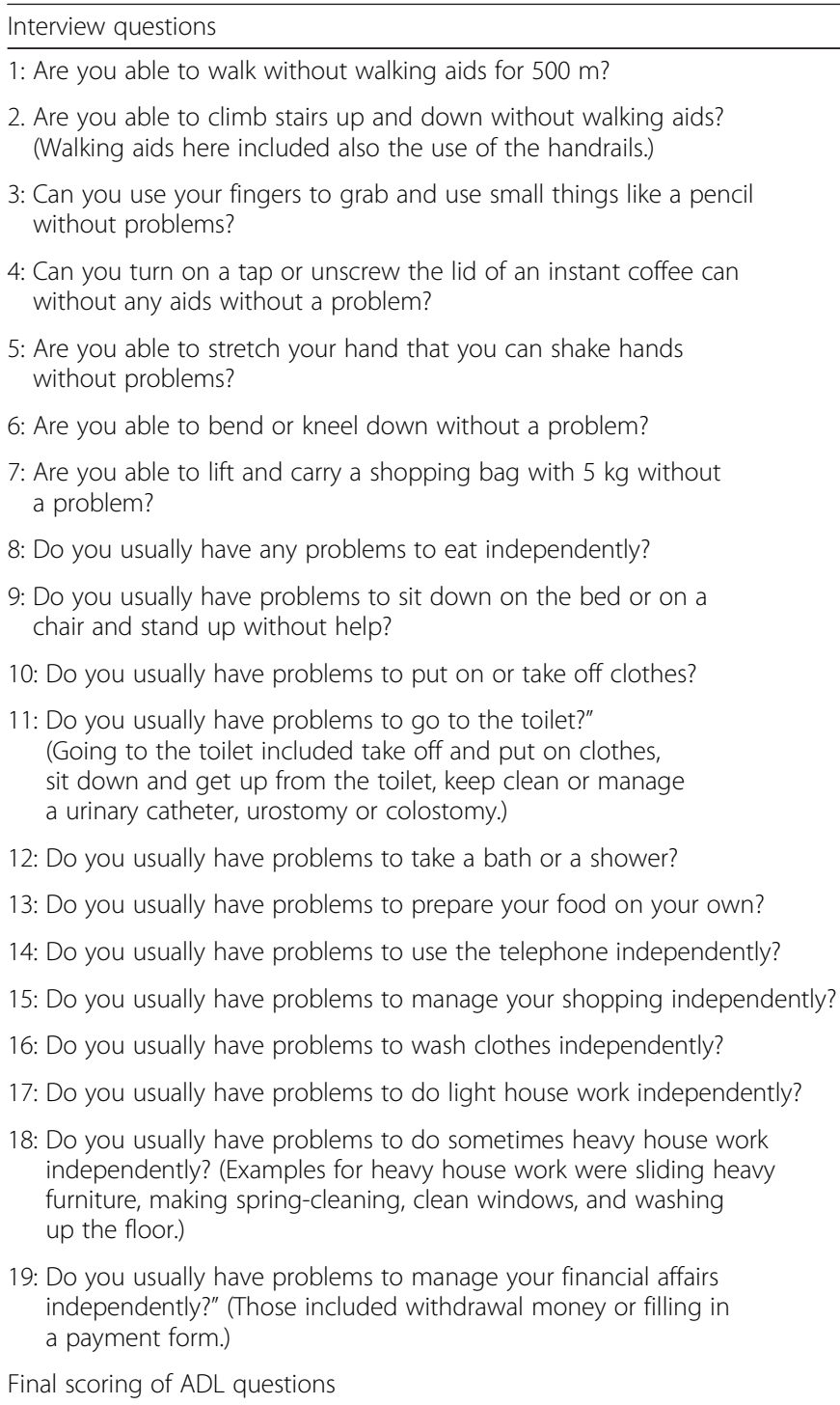

19: Do you usually have problems to manage your financial affairs independently?" (Those included withdrawal money or filling in a payment form.)

Final scoring of $\mathrm{ADL}$ questions

\section{Scoring}

Questions 1 to 7 could be answered by "yes" or "no".

Questions 8 to 19 could be answered by "yes", "no", and "unsure". The answers "yes" and "unsure" were merged together as "having a problem".

\section{Analyses}

Descriptive statistics were used to calculate frequencies of problems in the ADLs. As co-variables in regression analyses sex, age, education level, pain intensity and presence of anxiety or depression were used. Age was grouped into steps of five years. Level of education was measured as ordinal variable with three levels of education: primary education (up to the age of 15 years), secondary education (apprenticeship or secondary school), and tertiary education (university or any other vocational training). Pain was assessed with the question "Did you suffer from severe pain in one or more than one body site during the last 12 months?". If this was answered with "yes", the respondents were shown a picture of the body with 14 different body sites and asked to show the region or regions in which they experienced the pain and for each body site with pain to indicate the intensity of pain on a 10-part visual analogue scale. The highest score in anybody site was used as co-variable in our analysis. Anxiety or depression was assessed with the question "Have you been suffering from anxiety or depression?”.

Bivariate analyses were undertaken by means of crosstabs, and group differences were assessed with the Pearson's $\mathrm{Chi}^{2}$-test. A procedure factor analysis (principal components analysis) was applied to analyse the main dimensions of the 19 items of ADL [16]. The internal consistency of these dimensions was determined by a reliability analysis (Cronbach's Alpha). The dichotomous ADL dimensions were then computed by 0 no deficit in the ADLs of the dimensions, and 1 having a deficit in any/at least one of the ADL items of the dimension. 
Binary logistic regression models were applied with the ADL dimensions as the dependent variables. The musculoskeletal diseases osteoarthritis, CBP, and osteoporosis, sex, the education level, and anxiety or depression were used as categorical, and age (in five year intervals) and pain intensity as metric independent variables in the logistic regression analyses. The results of all logistic regression models are presented as odds ratios with $95 \%$ confidence intervals. Nagelkerkes' $R^{2}$ is presented as a measure of model-fit. Calculations were done using the procedure of SPSS 20 [IBM].

\section{Results}

In people aged 65 years and older, representative for the Austrian population of this age, $36.1 \%$ of the population reported to have one of the three musculoskeletal diseases (Table 2), $23.1 \%$ were suffering from two of them and $9.2 \%$ were affected by all three of the diseases according to their own statements. Only $31.5 \%$ of the population aged 65 years and older had none of them. Table 2 depicts socio-demographic characteristics of all participants.

The principal components analysis revealed four major dimensions of ADLs (Table 3). One dimension comprised

Table 2 Sociodemographic characteristics of the participants

\begin{tabular}{lcc}
\hline Sociodemographic characteristics & $N$ & $\%$ \\
\hline Sex & 1259 & 40.7 \\
Male & 1838 & 59.3 \\
Female & & \\
Age & 1657 & 53.5 \\
Lower than 75 years & 1439 & 46.5 \\
Higher than 75 years & & \\
Education & 1428 & 46.1 \\
Primary education & 1512 & 48.8 \\
Secondary education & 157 & 5.1 \\
Tertiary education & & \\
Pain & 1350 & 43.6 \\
Severe pain in the last 7 days & 1747 & 56.4 \\
No severe pain in the last 7 days & & \\
Anxiety or depression & 347 & 11.2 \\
Yes & 2750 & 88.8 \\
No & & \\
Health condition(s) - self-reported & 1268 & 41.0 \\
Osteoarthritis & 1566 & 50.6 \\
Chronic back pain & 570 & 13.9 \\
Osteoporosis & 795 & \\
Osteoarthritis AND Chronic back pain & & \\
Osteoarthritis AND Osteoporosis & & \\
Chronic back pain AND Osteoporosis & & \\
\hline
\end{tabular}

ADL items, in which heavy burdens or far distances have to be managed, so we named it "intense ADLs". A second dimension consisted of basic instrumental activities of daily living (IADLs) like washing clothes, preparing food or doing light house work and we labelled it "basic IADLs". The third dimension was built with basic activities of daily living like personal hygiene, eating or dressing ("basic ADLs"). A fourth dimension contained items in which the hand and fingers are used ("hand-focused ADLs"). According to the Cronbach's alpha the first three dimensions showed an excellent, the fourth a fair reliability (Table 3 ).

$58.2 \%$ of the total analysed population had problems in the intense ADLs, $29.2 \%$ in basic IADLs, $23.0 \%$ in basic ADLs and $9.2 \%$ in hand-focussed ADLs. All four dimensions were significantly more often influenced in subjects with osteoarthritis, CBP or osteoporosis (Table 4; Table 5 shows the data for the combinations of the three health conditions).

In all participants taken together, the ADL which caused the problem in the highest proportion of subjects was "doing heavy housework" (43.9\%), followed by "bend or kneel down" (39.3\%), "climbing stairs up and down without walking aids" (23.1\%), and "walking 500 $\mathrm{m}$ without walking aids" (22.8 \%). In Table 4, the proportion of subjects with and without musculoskeletal diseases who reported deficits in various ADLs is shown. All assessed items of ADL were significantly more often impaired in people with osteoporosis compared to those without osteoporosis. Furthermore in people with osteoarthritis and in people with CBP, a large number of ADLs were significantly more often affected compared to those without these diseases (Table 4). Compared to people with osteoarthritis, a higher proportion of people with osteoporosis reported deficits in all ADL items. Furthermore, a higher proportion of people with osteoarthritis reported ADL problems than people with CBP. Table 5 shows ADL problems/deficits in combinations of the three health conditions.

In Table 6, the factors that were found to influence the four dimensions of ADLs in the multivariate logistic regression analysis are presented. Osteoarthritis was associated with a $68 \%$ higher chance of a detraction of intense ADLs, and with a $32 \%$ higher chance of impairment in hand-focussed ADLs. After adjustment, CBP was not associated with problems in any dimension of ADL. Osteoporosis increased the chance of detraction in intense ADLs by $45 \%$ and of basic IADLs by $37 \%$.

Female sex was associated with an increased risk of deficits in intense ADLs, but with a decreased risk of deficits in basic IADLs. Age was associated with an increased risk of detraction in all four dimensions of ADL. The level of education had mostly no influence on ADL performance; however, secondary education was, compared to tertiary 
Table 3 Dimensions of activities of daily living according to a rotated factor analysis

\begin{tabular}{|c|c|c|c|c|}
\hline & Dimension 1 & Dimension 2 & Dimension 3 & Dimension 4 \\
\hline Title & Intense ADLs & Basic IADLs & Basic ADLs & Hand-focused ADLs \\
\hline Components & $\begin{array}{l}1 \text { Lift and carry a shopping bag with } 5 \mathrm{~kg} \\
2 \text { Bend or kneel down } \\
3 \text { Climbing stairs up and down without } \\
\text { walking aids } \\
4 \text { Walking } 500 \text { m without walking aids } \\
5 \text { Do regularly heavy house work }\end{array}$ & $\begin{array}{l}1 \text { Wash clothes independently } \\
2 \text { Prepare food } \\
3 \text { Do regularly light house work } \\
4 \text { Manage financial affairs independently } \\
5 \text { Make telephone calls independently } \\
6 \text { Shopping }\end{array}$ & $\begin{array}{l}1 \text { Go to the toilet } \\
2 \text { Eat independently } \\
3 \text { Put on and take off clothes } \\
4 \text { Sit down on a chair or bed and } \\
\text { stand up } \\
5 \text { Take a bath or a shower }\end{array}$ & $\begin{array}{l}1 \text { Stretch hand and shake hands } \\
2 \text { Turn on a tap or unscrew a can } \\
3 \text { Use fingers to grab and use small } \\
\text { things }\end{array}$ \\
\hline Description & $\begin{array}{l}\text { ADL items, in which heavy burdens } \\
\text { or far distances have to be managed }\end{array}$ & $\begin{array}{l}\text { ADL items, which are necessary to live } \\
\text { independently in the community }\end{array}$ & $\begin{array}{l}\text { ADL items, which consist of basic } \\
\text { self-care tasks }\end{array}$ & $\begin{array}{l}\text { ADL items, in which the hand and fingers } \\
\text { are used that focus on shaking, turning and } \\
\text { handling small gadgets }\end{array}$ \\
\hline Cronbach's alpha & 0.869 & 0.829 & 0.847 & 0.597 \\
\hline
\end{tabular}


Table 4 Proportion (percent) of 3097 community-dwelling subjects who reported problems or deficits in various activities of daily living (ADLs)

\begin{tabular}{|c|c|c|c|c|c|c|c|c|c|}
\hline \multirow[b]{2}{*}{ ADL problems/deficits (\%) } & \multicolumn{3}{|c|}{ Osteoarthritis } & \multicolumn{3}{|c|}{ Chronic back pain } & \multicolumn{3}{|c|}{ Osteoporosis } \\
\hline & Yes & No & $p$-value & Yes & No & $p$-value & Yes & No & $p$-value \\
\hline Walking $500 \mathrm{~m}$ without walking aids & 32.3 & 16.1 & $<0.001$ & 26.1 & 19.4 & $<0.001$ & 35.4 & 19.9 & $<0.001$ \\
\hline Climbing stairs up and down without walking aids & 32.9 & 16.2 & $<0.001$ & 27.3 & 18.7 & $<0.001$ & 37.5 & 19.8 & $<0.001$ \\
\hline Use fingers to grab and use small things & 8.2 & 3.6 & $<0.001$ & 6.3 & 4.6 & 0.032 & 10.4 & 4.4 & $<0.001$ \\
\hline Turn on a tap or unscrew a can & 8.1 & 3.8 & $<0.001$ & 6.9 & 4.3 & 0.002 & 10.2 & 4.6 & $<0.001$ \\
\hline Stretch hand and shake hands & 3.2 & 0.9 & $<0.001$ & 2.5 & 1.2 & 0.010 & 3.5 & 1.5 & 0.001 \\
\hline Bend or kneel down & 57.3 & 26.8 & $<0.001$ & 48.0 & 30.4 & $<0.001$ & 58.1 & 35.0 & $<0.001$ \\
\hline Lift and carry a shopping bag with 5 kg & 44.8 & 22.9 & $<0.001$ & 37.3 & 26.3 & $<0.001$ & 53.2 & 27.0 & $<0.001$ \\
\hline Eat independently & 7.6 & 6.5 & 0.219 & 7.0 & 6.9 & 0.912 & 9.8 & 6.3 & 0.003 \\
\hline Sit down on a chair or bed and stand up & 14.9 & 9.6 & $<0.001$ & 13.8 & 8.5 & $<0.001$ & 18.6 & 9.5 & $<0.001$ \\
\hline Put on and take off clothes & 16.6 & 10.4 & $<0.001$ & 14.9 & 10.9 & 0.001 & 18.1 & 11.8 & $<0.001$ \\
\hline Go to the toilet & 8.2 & 6.8 & 0.154 & 7.5 & 7.3 & 0.758 & 10.5 & 6.7 & 0.002 \\
\hline Take a bath or a shower & 22.2 & 12.8 & $<0.001$ & 19.2 & 14.1 & $<0.001$ & 25.8 & 14.6 & $<0.001$ \\
\hline Prepare food & 21.7 & 15.3 & $<0.001$ & 19.7 & 16.1 & 0.010 & 23.3 & 16.9 & 0.003 \\
\hline Make telephone calls independently & 6.4 & 5.1 & 0.140 & 5.7 & 5.6 & 0.937 & 7.4 & 5.3 & 0.049 \\
\hline Go shopping independently & 27.9 & 15.1 & $<0.001$ & 23.5 & 17.2 & $<0.001$ & 31.1 & 17.9 & $<0.001$ \\
\hline Wash clothes independently & 24.8 & 17.4 & $<0.001$ & 22.0 & 18.9 & 0.037 & 24.4 & 19.6 & 0.010 \\
\hline Do regularly light house work & 21.4 & 13.9 & $<0.001$ & 19.6 & 14.2 & $<0.001$ & 24.4 & 15.2 & $<0.001$ \\
\hline Do regularly heavy house work & 57.4 & 34.6 & $<0.001$ & 49.2 & 38.6 & $<0.001$ & 62.1 & 39.8 & $<0.001$ \\
\hline Manage financial affairs independently & 15.4 & 8.9 & $<0.001$ & 11.9 & 11.1 & 0.496 & 16.4 & 10.4 & $<0.001$ \\
\hline ADL dimension $1^{*}$ & 74.5 & 46.9 & $<0.001$ & 65.9 & 50.3 & $<0.001$ & 77.5 & 53.8 & $<0.001$ \\
\hline ADL dimension $2^{*}$ & 35.6 & 24.7 & $<0.001$ & 32.2 & 26.1 & $<0.001$ & 37.9 & 27.2 & $<0.001$ \\
\hline ADL dimension $3^{*}$ & 29.7 & 18.3 & $<0.001$ & 26.2 & 19.7 & $<0.001$ & 34.6 & 20.3 & $<0.001$ \\
\hline ADL dimension $4^{*}$ & 13.6 & 6.1 & $<0.001$ & 11.2 & 7.1 & $<0.001$ & 15.8 & 7.7 & $<0.001$ \\
\hline
\end{tabular}

The $\mathrm{p}$-values refer to differences between those with and without the respective musculoskeletal disorder and were calculated with the Pearson's Chi ${ }^{2}$ test *ADL dimensions are described in Table 3

education associated with a lower risk for impairment in basic IADLs like household keeping. Pain intensity increased the chance of deficits of all dimension of ADL. The greatest effect on all dimensions of ADLs was found regarding self-reported anxiety of depression. Those mental diseases doubled to tripled the risk for impairment in the respective dimensions of ADL.

\section{Discussion}

This study showed that older adults with and without osteoarthritis, CBP and osteoporosis in a populationbased survey in Austria experienced considerable problems in performing their ADLs - despite that they all were "receiving" the "normal" Austrian health care. Only $40 \%$ of the people aged $\geq 65$ years had no ADL limitations in intense ADLs (dimension 1). This may show that there is additional need for interventions that focus on ADLs. The number of older adults with musculoskeletal complaints who experience problems in household activities and mobility in this study clearly demonstrates the need for functional assessment and corresponding interventions to prevent worsening and further ADL-, health and social problems which would consequently raise also costs for the individual and society. This group of people should therefore be a priority target for specialists of physical medicine and rehabilitation and occupational therapists, as well as other health professionals who aim to achieve optimal functioning in daily life. Physicians, nurses and therapists may be recommended to screen older adults for ADL problems and in case refer them to these specialists. If ADL problems are not taken seriously e.g. due to a musculoskeletal disease, these problems consequently increase leading to additional costs for health and social care [17].

Interestingly, similar activities were experienced more often as problematic across these three health conditions. Furthermore, the ADLs which caused problems in the highest proportion of subjects are in two main "areas": mobility and housework. The following two chapters within the ICF component activities and participation 
Table 5 Combinations of the three health conditions

\begin{tabular}{|c|c|c|c|c|c|c|c|c|c|}
\hline \multirow[b]{2}{*}{ ADL problems/deficits $(\%)$} & \multicolumn{3}{|c|}{$\begin{array}{l}\text { Osteoarthritis and chronic } \\
\text { back pain }\end{array}$} & \multicolumn{3}{|c|}{$\begin{array}{l}\text { Osteoarthritis and } \\
\text { osteoporosis }\end{array}$} & \multicolumn{3}{|c|}{$\begin{array}{l}\text { Chronic back pain and } \\
\text { osteoporosis }\end{array}$} \\
\hline & Yes & No & $p$-value & Yes & No & $p$-value & Yes & No & $p$-value \\
\hline Walking $500 \mathrm{~m}$ without walking aids & 34.3 & 18.7 & $<0.001$ & 43.6 & 19.9 & $<0.001$ & 38.4 & 20.4 & $<0.001$ \\
\hline Climbing stairs up and down without walking aids & 35.4 & 18.8 & $<0.001$ & 44.4 & 20.2 & $<0.001$ & 40.0 & 20.5 & $<0.001$ \\
\hline Use fingers to grab and use small things & 9.6 & 4.0 & $<0.001$ & 12.5 & 4.5 & $<0.001$ & 9.9 & 4.8 & $<0.001$ \\
\hline Turn on a tap or unscrew a can & 9.9 & 4.1 & $<0.001$ & 12.5 & 4.7 & $<0.001$ & 10.7 & 4.8 & $<0.001$ \\
\hline Stretch hand and shake hands & 4.4 & 1.0 & $<0.001$ & 4.1 & 1.6 & 0.001 & 3.5 & 1.6 & 0.011 \\
\hline Bend or kneel down & 61.3 & 31.7 & $<0.001$ & 68.8 & 35.3 & $<0.001$ & 61.6 & 35.9 & $<0.001$ \\
\hline Lift and carry a shopping bag with $5 \mathrm{~kg}$ & 46.7 & 26.7 & $<0.001$ & 59.1 & 28.2 & $<0.001$ & 55.3 & 28.3 & $<0.001$ \\
\hline Eat independently & 7.9 & 6.6 & 0.223 & 10.6 & 6.5 & 0.004 & 9.9 & 6.5 & 0.013 \\
\hline Sit down on a chair or bed and stand up & 17.1 & 9.2 & $<0.001$ & 20.7 & 9.9 & $<0.001$ & 19.1 & 10.0 & $<0.001$ \\
\hline Put on and take off clothes & 18.6 & 11.0 & $<0.001$ & 19.5 & 12.1 & $<0.001$ & 18.9 & 12.1 & $<0.001$ \\
\hline Go to the toilet & 7.9 & 7.2 & 0.509 & 10.6 & 7.0 & 0.012 & 9.2 & 7.2 & 0.150 \\
\hline Take a bath or a shower & 24.2 & 14.0 & $<0.001$ & 29.9 & 14.9 & $<0.001$ & 25.8 & 15.3 & $<0.001$ \\
\hline Prepare food & 23.6 & 15.9 & $<0.001$ & 26.4 & 16.8 & $<0.001$ & 23.8 & 17.0 & 0.001 \\
\hline Make telephone calls independently & 6.9 & 5.2 & 0.073 & 6.8 & 5.5 & 0.313 & 8.7 & 5.2 & 0.005 \\
\hline Go shopping independently & 30.7 & 16.8 & $<0.001$ & 35.2 & 18.4 & $<0.001$ & 33.7 & 18.3 & $<0.001$ \\
\hline Wash clothes independently & 27.0 & 18.2 & $<0.001$ & 28.2 & 19.4 & $<0.001$ & 25.7 & 19.7 & 0.005 \\
\hline Do regularly light house work & 24.7 & 14.3 & $<0.001$ & 27.7 & 15.5 & $<0.001$ & 25.8 & 15.6 & $<0.001$ \\
\hline Do regularly heavy house work & 59.0 & 38.7 & $<0.001$ & 68.3 & 40.6 & $<0.001$ & 62.3 & 41.2 & $<0.001$ \\
\hline Manage financial affairs independently & 16.1 & 9.9 & $<0.001$ & 17.3 & 10.7 & $<0.001$ & 17.6 & 10.6 & $<0.001$ \\
\hline ADL dimension $1^{*}$ & 69.2 & 46.3 & $<0.001$ & 79.1 & 48.5 & $<0.001$ & 73.7 & 48.9 & $<0.001$ \\
\hline $\mathrm{ADL}$ dimension $2^{*}$ & 39.7 & 25.6 & $<0.001$ & 43.6 & 27.2 & $<0.001$ & 40.9 & 27.5 & $<0.001$ \\
\hline ADL dimension $3^{*}$ & 64.2 & 36.2 & $<0.001$ & 71.2 & 39.7 & $<0.001$ & 66.3 & 40.0 & $<0.001$ \\
\hline ADL dimension $4^{*}$ & 16.6 & 6.6 & $<0.001$ & 19.0 & 7.8 & $<0.001$ & 16.6 & 8.1 & $<0.001$ \\
\hline
\end{tabular}

include all these activities: "Chapter 4 Mobility" and "Chapter 6 Domestic life". Doing heavy housework can be linked to the ICF category "d640 Doing housework", Bend or kneel down to "d410 Changing basic body position", Climbing stairs up and down without walking aids to "d4551 Climbing" and Walking $500 \mathrm{~m}$ without walking aids to "d4500 Walking short distances (less than a kilometre)". Dimensions 1 (Intense ADLs) and 4 (Hand-focused ADLs) in Table 3 deal also with mobility and housework because the ICF "Chapter 4 Mobility" includes also hand-based activities such as fine hand use (d440) or lifting and carrying objects (d430). Hand-based activities were one separate dimension in the factor analysis on ADL problems in these 3 musculoskeletal diseases. While this is obvious in osteoarthritis (osteoarthritis is most common in hips, knees and hands), back pain and osteoporosis do not mainly affect the hands. Those two areas (and corresponding ICF chapters) mobility and domestic life could therefore be important areas to consider in the assessment of older adults with different musculoskeletal complaints.

In Table 4, ADL deficits were significantly more often reported by people with the three musculoskeletal conditions (compared to people without the respective conditions), while in Table 6, this relationship between ADL problems and diseases appears to be considerably reduced. We therefore concluded that the ADL deficits are partly related to the factors for which we controlled in the multivariate models, such as pain, mental health [18-20] etc. However, some relationships such as between osteoarthritis and ADL deficits in dimension 1 and 4 or osteoporosis and ADL deficits in dimension 1 and 2 appear also in the models - indicating that ADL problems in these dimensions are related to these conditions and not influenced by the other factors controlled for in the models.

Female sex was associated with increased deficits in intense ADLs (dimension 1) and decreased deficits in basic ADLs (dimension 2). This may show traditional 
Table 6 Logistic regression results (odds ratios, ORs) of having deficits in activities of daily living of various dimensions

\begin{tabular}{|c|c|c|c|c|c|c|c|c|c|}
\hline & & \multicolumn{8}{|c|}{ Dependent variables } \\
\hline & & \multicolumn{2}{|c|}{ Dimension 1} & \multicolumn{2}{|c|}{ Dimension 2} & \multicolumn{2}{|c|}{ Dimension 3} & \multicolumn{2}{|c|}{ Dimension 4} \\
\hline & & \multicolumn{2}{|c|}{ Intense ADLs } & \multicolumn{2}{|c|}{ Basic IADLs } & \multicolumn{2}{|c|}{$\underline{\text { Basic ADLs }}$} & \multicolumn{2}{|c|}{ Hand-focussed ADLs } \\
\hline & & OR & $95 \% \mathrm{Cl}$ & $\mathrm{OR}$ & $95 \% \mathrm{Cl}$ & $\mathrm{OR}$ & $95 \% \mathrm{Cl}$ & $\mathrm{OR}$ & $95 \% \mathrm{Cl}$ \\
\hline \multirow[t]{10}{*}{ Independent variables } & Osteoarthritis & 1.68 & $1.39-2.03$ & 1.09 & $0.90-1.32$ & 0.98 & $0.80-1.20$ & 1.32 & $1.00-1.75$ \\
\hline & Chronic back pain & 1.19 & $0.99-1.42$ & 0.94 & $0.78-1.14$ & 0.95 & $0.78-1.16$ & 1.03 & $0.78-1.36$ \\
\hline & Osteoporosis & 1.45 & $1.11-1.88$ & 1.37 & $1.08-1.73$ & 1.24 & $0.97-1.57$ & 1.25 & $0.92-1.71$ \\
\hline & Female sex (ref: male) & 1.24 & $1.03-1.50$ & 0.41 & $0.33-0.50$ & 1.07 & $0.86-1.32$ & 1.02 & $0.76-1.38$ \\
\hline & Age (5 year intervals) & 1.86 & $1.74-2.00$ & 1.80 & $1.68-1.93$ & 1.79 & $1.66-1.92$ & 1.47 & $1.34-1.62$ \\
\hline & Primary education (ref: tertiary) & 1.17 & $0.79-1.74$ & 0.90 & $0.60-1.36$ & 0.96 & $0.60-1.55$ & 1.24 & $0.59-2.62$ \\
\hline & Secondary education (ref: tertiary) & 0.85 & $0.58-1.25$ & 0.59 & $0.39-0.88$ & 0.73 & $0.46-1.18$ & 1.21 & $0.58-2.55$ \\
\hline & Pain intensity (per point) & 1.26 & $1.22-1.31$ & 1.15 & $1.12-1.18$ & 1.18 & $1.14-1.22$ & 1.15 & $1.11-1.20$ \\
\hline & Anxiety or depression & 2.63 & $1.90-3.64$ & 2.31 & $1.79-2.99$ & 2.41 & $1.86-3.14$ & 2.84 & $2.09-3.86$ \\
\hline & Nagelkerke's $\mathrm{R}^{2}$ & \multicolumn{2}{|l|}{0.378} & \multicolumn{2}{|c|}{0.250} & \multicolumn{2}{|c|}{0.257} & \multicolumn{2}{|l|}{0.166} \\
\hline
\end{tabular}


gender differences in the performance of ADLs in Austria, in that women still take over more household tasks and are more likely limited in terms of "heavy" activities such as being included in dimension 1 . In one of our recent qualitative studies, the life stories of women and men with arthritis reflected how contextual factors (such the healthcare system, the support of families and social and cultural values) shaped their everyday activities. Men for example had more difficulties to develop a nonpaid-work related role in their lives than women [21]. Especially dimension 2 (basic IADLs) in our study includes several activities that are primarily done by women in Austria, such as washing clothes, preparing food and regular light housework. This dimension seems to be an important aspect for the possibility of living independently in the community, whereas the activities in dimension 1 could be taken over by social networks.

While the ICF is a comprehensive framework including a classification of functioning in daily life, other definitions that characterise an activity as either ADL or IADL exist. Basic ADLs (BADLs) consist of self-care tasks, including bathing and showering (washing the body), bowel and bladder management (recognizing the need to relieve oneself), dressing, eating (including chewing and swallowing), feeding (setting up food and bringing it to the mouth), functional mobility (moving from one place to another while performing activities), personal device care, personal hygiene and grooming (including washing hair), sexual activity and toilet hygiene (completing the act of relieving oneself) [22]. Instrumental activities of daily living (IADLs) are not necessary for fundamental functioning, but they let an individual live independently in a community. Examples are housework, taking medications as prescribed, managing money, shopping for groceries or clothing, use of telephone or other form of communication, using technology and transportation within the community [23].

Participants with only secondary education were less likely to have ADL problems in dimension 2, while age and pain were clearly associated with more ADL problems in all dimensions. While age without any health problems also increases ADL problems, the highest ORs in our study were associated with anxiety and depression. However, we cannot determine the causal relationship because anxiety and depression can lead to increased ADL problems, but also vice-versa, ADL problems leading to increased anxiety and depression.

Chapter 5 of the ICF "Self-care" was mostly represented in dimension 3 and presented a dependency on age, anxiety and depression. The age-dependent loss of independent eating, dressing or toileting is an important aspect because of the rising age of the population.

A strength of our study is the fact that the survey was population-based. Thus, selection bias that would occur, if only participants living in clinical or nursing home settings were interviewed, could be avoided. Some limitations of our study have to be mentioned. Data were gathered in the Austrian Health Survey and we could not influence the list of activities that were included. Also there was no question on the priority of the activities, nor a question asking each individual to name one primary ADL-problem. Diagnoses were self-reported; people thus may have overestimated certain symptoms, such as joint pain, and on the other hand may not have known about other health conditions, such as osteoporosis. As Nagelkerke's R2 ranged between 0.166 and 0.378 , other factors may have contributed to ADL problems that were not captured in this population-based survey, such as gross and fine motor skills, balance, strength and sensory functions, as well as personal and environmental factors. All questions focused mainly on activities, but not on body functions or structures, nor on environmental factors influencing the performance of these activities. Furthermore, the question for anxiety and depression is very personal and will therefore be not always honestly answered in such an interview survey.

Cronbach's alpha in the $4^{\text {th }}$ dimension was low. A possible reason can be that all three items in the $4^{\text {th }}$ dimension included two concepts to score in one item (stretch hand AND shake hands; turn on a tap OR unscrew a can; use fingers to grab AND use small things) - this is difficult to sore and participants may have understood (and consequently scored) these items differently [24].

\section{Conclusion}

This population-based survey indicates that people with self-reported osteoporosis, osteoarthritis and CBP have considerable ADLs problems despite "normal" Austrian health care. Older adults with musculoskeletal complaints could be a special target group for ADL specialists such as physical medicine and rehabilitation physicians and occupational therapists. More attention should be paid to the high impact of pain (intensity) as well as anxiety and depression on ADLs.

\section{Ethics approval}

The secondary analysis of the AT-HIS database which was used for this study was approved by the Ethics Committee of the Medical University Vienna (EC\# 770/2011).

\section{Data availability}

All relevant raw data will be freely available to any scientist wishing to use them for non-commercial purposes, without breaching participant confidentiality.

\section{Abbreviations}

ADLS: Activities of daily living; CBP: Chronic back pain; WHO: World Health Organisation; ICF: International Classification of Functioning Disability and Health; AT-HIS: Austrian Health Interview Survey. 


\section{Competing interests}

The authors declare that they have no competing interests.

\section{Authors' contributions}

TS participated in the analyses, carried out the interpretation of the results and drafted the manuscript. KP participated in the analyses and the interpretation of the results. RC participated in the interpretation of the results. TD carried out the analyses and the interpretation of the results. All authors read and approved the final manuscript.

\section{Acknowledgement}

We thank all the people who participated in the Austrian health survey. Furthermore, we are thankful to Prof. Veronika Fialka-Moser who sadly passed away recently for having the idea for this study. Parts of the results shown in this paper have been presented as a poster at the national Austrian public health congress in St. Pölten, Austria, in May 2014.

\section{Funding}

This study did not receive specific funding. The database used for our analysis was the Austrian Health Interview Survey.

\section{Author details}

'Section for Outcomes Research, Center for Medical Statistics, Informatics, and Intelligent Systems, Medical University of Vienna and Division of Rheumatology, Department of Internal Medicine III, Medical University of Vienna, Spitalgasse 23, 1090 Vienna, Austria. ${ }^{2}$ Department of Physical Medicine and Rehabilitation, Medical University of Vienna, Vienna, Austria. ${ }^{3}$ Institute of Social Medicine, Centre for Public Health, Medical University of Vienna, Vienna, Austria.

Received: 6 May 2015 Accepted: 22 March 2016

Published online: 28 March 2016

\section{References}

1. Woolf AD, Erwin J, March L. The need to address the burden of musculoskeletal conditions. Best Pract Res Clin Rheumatol. 2012;26(2):183-224.

2. WHO Technical Report Series, N. The Burden of Musculoskeletal Conditions at the Start of the New Millenium. Geneva: World Health Organization; 2003.

3. Choong P, Brooks P. Achievements during the Bone and Joint Decade 2000-2010. Best Pract Res Clin Rheumatol. 2012;26(2):173-81.

4. Dorner TE et al. Austrian Osteoporosis Report: epidemiology, lifestyle factors, public health strategies. Wien Med Wochenschr. 2009;159(9-10):221-9.

5. Dorner TE, Stein KV. Prevalence and status quo of osteoarthritis in Austria. Analysis of epidemiological and social determinants of health in a representative cross-sectional survey. Wien Med Wochenschr. 2013;163(9-10):206-11.

6. WHO. ICF - International Classification of Functioning, Disability and Health. Geneva: World Health Organization; 2001

7. Stamm TA et al. I have a disease, but I am not ill: A narrative study of occupational balance in people with rheumatoid arthritis. OTJR: Occupation, participation and health. 2008;29(1):32-9.

8. Stamm TA et al. Concepts Important to People with Psoriatic Arthritis are not Adequately Covered by Standard Measures of Functioning. Arthritis Rheum. 2007:57(3):487-94.

9. Stamm TA et al. Patient perspective of hand osteoarthritis in relation to concepts covered by instruments measuring functioning - A qualitative European multi-centre study. Ann Rheum Dis. 2008:68:1453-60.

10. Hewlett S, Smith AP, Kirwan JR. Measuring the Meaning of Disability in Rheumatoid Arthritis: The Personal Impact Health Assessment Questionnaire (PI HAQ). Ann Rheum Dis. 2003;61:986-93.

11. Mattsson M. et al. Personal factors in systemic sclerosis and their coverage by patient-reported outcome measures: A multicentre European qualitative study and literature review. Eur J Phys Rehabil Med. 2015;51(4):405-21. Epub 2015 Jan 9.

12. Townsend, E. and H. Polatajko, Enabling Occupation II: Advancing an Occupational Therapy Vision for Health, Well-being \& Justice through Occupation. 2007: Canadian Association of Occupational Therapists.

13. Steultjens EM et al. Occupational therapy for community dwelling elderly people: a systematic review. Age Ageing. 2004;33(5):453-60.
14. Statistik Austria (Hrsg.) im Auftrag von Bundesministerium für Gesundheit, F.u.J. Österreichische Gesundheitsbefragung 2006/07. Hauptergebnisse und methodische Dokumentation. 2007, Vienna: Statistik Austria.

15. Aromaa A et al. Evaluation of Health Interview Surveys and Health Examination Surveys in the European Union. Eur J Public Health. 2003;13(3 Suppl):67-72.

16. Tabachnick BG, Fidell LS. Using Multivariate Statistics. 3rd ed. New York: Harper Collins; 1996

17. Song J, Chang RW, Dunlop DD. Population impact of arthritis on disability in older adults. Arthritis Rheum. 2006;55(2):248-55.

18. Meyer T, Cooper J, Raspe H. Disabling low back pain and depressive symptoms in the community-dwelling elderly: a prospective study. Spine (Phila Pa 1976). 2007:32(21):2380-86.

19. Mallen CD, Peat G. Screening older people with musculoskeletal pain for depressive symptoms in primary care. Br J Gen Pract. 2008;58(555):688-93.

20. Pincus T. et al. A systematic review of psychological factors as predictors of chronicity/disability in prospective cohorts of low back pain. Spine (Phila Pa 1976). 2002;27(5):E109-20.

21. Stamm TA et al. Life stories of people with rheumatoid arthritis who retired early: how gender and other contextual factors shaped their everyday activities, including paid work. Muscoskel Care. 2010;8(2):78-86.

22. Roley SS et al. Occupational therapy practice framework: domain \& practice, 2nd edition. Am J Occup Ther. 2008;62(6):625-83.

23. Bookman A et al. Family Caregiver Handbook. Cambridge: Massachusetts Institute of Technology; 2013.

24. Stamm TA et al. Measuring functioning in patients with hand osteoarthritiscontent comparison of questionnaires based on the International Classification of Functioning, Disability and Health (ICF). Rheumatology (Oxford). 2006:45(12):1534-41.

\section{Submit your next manuscript to BioMed Central and we will help you at every step:}

- We accept pre-submission inquiries

- Our selector tool helps you to find the most relevant journal

- We provide round the clock customer support

- Convenient online submission

- Thorough peer review

- Inclusion in PubMed and all major indexing services

- Maximum visibility for your research

Submit your manuscript at www.biomedcentral.com/submit 